\title{
Commentary: Perception and Reality: Why a Wholly Empirical Paradigm is Needed to Understand Vision
}

\author{
Luis H. Favela * \\ Department of Philosophy and Cognitive Sciences Program, University of Central Florida, Orlando, FL, USA
}

Keywords: affordances, ecological psychology, information, perceptual systems, retinal image, vision, visual perception

\section{A commentary on}

Perception and Reality: Why a Wholly Empirical Paradigm is Needed to Understand Vision by Purves, D., Morgenstern, Y., and Wojtach, W. T. (2015). Front. Syst. Neurosci. 9:156. doi: $10.3389 /$ fnsys.2015.00156

This commentary attempts to make two points: First, although Purves, Morgenstern, and Wojtach (PMW) are likely correct that the retinal image alone is an insufficient basis for successful visually guided action (Purves et al., 2015a, p. 1), their "vision as reflexive" strategy emphasizes the perceptual associations and neural portions of the visual system at the cost of understating the central role environmental information plays in vision. Second, although PMW are correct that early empirical strategies did not sufficiently incorporate neural aspects of the visual system (pp. 2-4), recent attempts to demonstrate how affordances relate to the nervous system help demonstrate that ecological psychology (EP, Gibson, 1966/1983, 1979/1986) remains a viable empirical framework for investigating and explaining vision.

EP is in agreement with PMW that retinal images alone are insufficient for visually guided

OPEN ACCESS

Edited by:

Mikhail Lebedev,

Duke University, USA

Reviewed by:

Ivan N. Pigarev,

Institute for Information Transmission

Problems (RAS), Russia

*Correspondence:

Luis H. Favela

luis.favela@ucf.edu

Received: 04 August 2016 Accepted: 06 September 2016 Published: 21 September 2016

Citation: Favela LH (2016) Commentary: Perception and Reality: Why a Wholly Empirical Paradigm is Needed to Understand Vision.

Front. Syst. Neurosci. 10:77. doi: 10.3389/fnsys.2016.00077 action (Purves et al., 2015a, p. 1). PMW’s “vision as reflexive" strategy (Purves et al., 2015a) claims that the link between stimulus and behavior that gives rise to visual perceptions "does not entail representing reality as such" (Purves et al., 2015b, p. 2). What matters for vision is the strength of reflexive bonds underlying perceptual associations that are reinforced over evolutionary timescales (Purves et al., 2015a, pp. 6-8; Purves et al., 2015b, p. 2). Although there are parts of this "reflexive" strategy that are congruent with EP, the inferred, indirect, and representational conception of vision on offer by PMW is incompatible with EP's central theoretical commitments.

EP emphasizes the idea that vision occurs in perceptual systems, where "perceptual system" refers to the animal-environment system (Favela and Chemero, 2016). When visually-guided action occurs in animals like us, it does so with our eyes connected to a brain, in a head, on a neck, on a body, with legs that move in particular ways while engaging with an environment with particular features. Understood in this way, vision is just as much action as perception, and it is an action that unfolds over time. Though the retinal image alone may not be sufficient to specify properties of the environment such as size and distance, environmental information such as optic energy structures are rich enough. "Information" is used in EP in terms of energy distributions (e.g., light and sound) specific to the layout of the world, and is revealed to an animal via its perceptual capacities as it moves. Along these lines, information is a systems-based, relational feature between animal and environment (Chemero, 2009). Energy distributions surrounding an animal can be rich with information that specifies action-relevant properties of the world (Fajen et al., 2008). Such properties are affordances, or opportunities for action. The perception of affordances has been demonstrated in investigations of the perception of gap sizes (Barac-Cikoja and Turvey, 1993), stand-on-ability 
of slopes (Fitzpatrick et al., 1994), catching moving objects (Oudejans et al., 1996), sit-on-ability (Mark, 1987), step-onability (Warren, 1984), and the pass-through-ability of apertures (Warren and Whang, 1987), just to name a few. Appealing to the structure of environmental information when accounting for the results is common across all of these perceptual experiments.

Temporality plays another major role in the ability of an animal to perceive affordances. Consider that a tree's distance is not specified by the retinal image alone, i.e., a tree that is small and near would cast the same retinal image as one large and far. However, since animals are always in motion, environmental cues such as motion parallax can facilitate the specification of features of objects such as size and distance. These considerations lend support to the current claim that although PMW's "vision as reflexive" strategy is correct to shift focus away from the retinal image as the basis of vision, they need not understate the richness of information available in the environment to specify features relevant to visually-guided behavior. Furthermore, the sample of studies above lend support to the notion that, contra PMW, environmental information can specify an animal's reality as such.

Next, I draw attention to the continued viability of EP as an empirical framework for investigating and explaining vision. PMW state that, like other early empirical strategies, EP has, "suffered from an absence of ties to the structure and function of animal visual systems" (Purves et al., 2015a, p. 3). This is a justified criticism. Although ecological psychologists do not study the nervous system per se (e.g., single neuron recordings, etc.), investigations friendly to EP at the intersection of the neural sciences and perceptual psychology have begun to connect research on affordance perception and associated neural physiology. Directly inspired by Gibson, Cisek's "affordance competition hypothesis" (Cisek, 2007; Cisek and Kalaska, 2010) takes an embodied, sensorimotor approach to explaining the neural underpinnings of how animals make action selections

\section{REFERENCES}

Barac-Cikoja, D., and Turvey, M. T. (1993). Haptically perceiving size at a distance. J. Exp. Psychol. Gen. 122, 347-370. doi: 10.1037/0096-3445.122.3.347

Chemero, A. (2009). Radical Embodied Cognitive Science. Cambridge, MA: MIT Press.

Cisek, P. (2007). Cortical mechanisms of action selection: the affordance competition hypothesis. Philos. Trans. R. Soc. 362, 1585-1599. doi: 10.1098/rstb.2007.2054

Cisek, P., and Kalaska, J. F. (2010). Neural mechanisms for interacting with a world full of action choices. Annu. Rev. Neurosci. 33, 269-298. doi: 10.1146/annurev.neuro.051508.135409

de Wit, M. M., van der Kamp, J., and Withagen, R. (2015). Visual illusions and direct perception: elaborating on Gibson's insights. New Ideas Psychol. 36, 1-9. doi: 10.1016/j.newideapsych.2014.07.001

Duran, B., and Thill, S. (2012). "Modeling interaction in multi-modal affordance processing with neural dynamics," in From Animals to Animats 12. 12th International Conference on Simulation of Adaptive Behavior, SAB 2012, Odense, Denmark, August 27-30, 2012 Proceedings, eds T. Ziemke, C. Balkenius, and J. Hallam (New York, NY: Springer), 75-84.

Fajen, B. R., Riley, M. A., and Turvey, M. T. (2008). Information, affordances, and the control of action in sport. Int. J. Sport Psychol. 40, 70-107. amid environments containing multiple relevant affordances. Duran and Thill (2012) present the "dynamic field theory" as a neurophysiologically inspired dynamical systems framework for modeling relationships among affordances and language. Mizelle et al. (2013) investigated potential neural networks underlying the perception of affordances that could facilitate goal-directed actions (i.e., "functional affordance") and those affordances that are actually used to achieve a goal (i.e., "physical affordance"). In addition, Young (2006) utilized evidence from patients with visual pathologies to develop a way to categorize affordances based upon their neurological underpinnings.

Though some of these studies modify Gibson's original conception of affordances (e.g., Gibson, 1979/1986), they remain compatible with the EP strategy as a whole, particularly the role affordances play in direct perception (cf. Michaels and Carello, 1981; de Wit et al., 2015). By incorporating relevant neurophysiological features of the visual system into accounts of affordance perception, EP remains a viable empirical framework for investigating and explaining vision. Moreover, it remains a framework that need not abandon its commitments to central tenets such as perceptual systems as the objects of investigation and environmental information as being rich enough to specify features of the world.

\section{AUTHOR CONTRIBUTIONS}

The author confirms being the sole contributor of this work and approved it for publication.

\section{ACKNOWLEDGMENTS}

I would like to thank Tony Chemero for discussion related to the concept of information in ecological psychology, and Mary Jean Amon for comments and edits. I would also like to thank a reviewer for helpful comments.

Favela, L. H., and Chemero, A. (2016). "The animal-environment system," in Foundations of Embodied Cognition: Perceptual and Emotional Embodiment, Vol. 1, eds Y. Coelllo and M. H. Fischer (New York, NY: Routledge), 59-74.

Fitzpatrick, P., Carello, C., Schmidt, R. C., and Corey, D. (1994). Haptic and visual perception of an affordance for upright posture. Ecol. Psychol. 6, 265-287. doi: 10.1207/s15326969eco0604_2

Gibson, J. J. (1966/1983). The Senses Considered as Perceptual Systems. Westport, CT: Greenwood Press.

Gibson, J. J. (1979/1986). The Ecological Approach to Visual Perception. Boston, MA: Houghton Mifflin.

Mark, L. S. (1987). Eyeheight-scaled information about affordances: a study of sitting and stair climbing. J. Exp. Psychol. 13, 683-703. doi: 10.1037/00961523.13.3.361

Michaels, C. F., and Carello, C. (1981). Direct Perception. Englewood Cliffs, NJ: Prentice-Hall, Inc.

Mizelle, J. C., Kelly, R. L., and Wheaton, L. A. (2013). Ventral encoding of functional affordances: a neural pathway for identifying errors in action. Brain Cogn. 82, 274-282. doi: 10.1016/j.bandc.2013.05.002

Oudejans, R. R. D., Michaels, C. F., Bakker, F. C., and Dolne, M. A. (1996). The relevance of action in perceiving affordances: perception of catchableness of fly balls. J. Exp. Psychol. Hum. Percept. Perform. 22, 879-891. doi: 10.1037/00961523.22.4.879 
Purves, D., Morgenstern, Y., and Wojtach, W. T. (2015a). Perception and reality: why a wholly empirical paradigm is needed to understand vision. Front. Syst. Neurosci. 9:156. doi: 10.3389/fnsys.2015.00156

Purves, D., Morgenstern, W., and Wojtach, W. T. (2015b). Will understanding vision require a wholly empirical paradigm? Front. Psychol. 6:1072. doi: 10.3389/fpsyg.2015.01072

Warren, W. H. Jr. (1984). Perceiving affordances: visual guidance of stair climbing. J. Exp. Psychol. 10, 683-703. doi: 10.1037/0096-1523.1 0.5.683

Warren, W. H. Jr., and Whang, S. (1987). Visual guidance of walking through apertures: body-scaled information for affordances. J. Exp. Psychol. Hum. Percept. Perform. 13, 371-383. doi: 10.1037/0096-1523.1 3.3.371
Young, G. (2006). Are different affordances subserved by different neural pathways? Brain Cogn. 62, 134-142. doi: 10.1016/j.bandc.2006.04.002

Conflict of Interest Statement: The author declares that the research was conducted in the absence of any commercial or financial relationships that could be construed as a potential conflict of interest.

Copyright (c) 2016 Favela. This is an open-access article distributed under the terms of the Creative Commons Attribution License (CC BY). The use, distribution or reproduction in other forums is permitted, provided the original author (s) or licensor are credited and that the original publication in this journal is cited, in accordance with accepted academic practice. No use, distribution or reproduction is permitted which does not comply with these terms. 